\title{
INVESTIGATION ON AGRICULTURAL LAND SELECTION USING HYBRID FUZZY LOGIC SYSTEM *
}

\author{
SUDHAKAR SENGAN $\dagger$ V. VIJAYAKUMAR SUJATHA KRISHNAMOORTHY§ S. GUNASEKARAN, C. SATHIYA \\ KUMAR, SARAVANAN PALANI**AND V. SUBRAMANIYASWAMY ${ }^{\dagger \dagger}$
}

\begin{abstract}
For maintaining the horticultural generation, Land Selection Investigation (LSI) is essential. Though incorporates estimation of the criteria assortment from the soil, territory to financial, market, and foundation, and these components are considerably enigmatically characterized and described by their inherent ambiguity. Multi-criteria basic leadership systems like positioning, rating, and so on are utilized for reasonableness examination. Master learning and judgment by leaders at different levels is integrated into this process. In the field of farming sciences, the Fuzzy Logic (FL) strategy has been effectively used to take care of numerous issues. Fuzzy with AHP is a Hybrid Fuzzy Logic (HFL) methodology. The policies Analytic Hierarchy Process (AHP), Fuzzy Numbers, Fuzzy Degree Investigation, Alpha Cut, and Lambda capacity are associated with it. As expressed, the procedure of necessary leadership includes a scope of criteria and a considerable measure of master learning and decisions. The components result from impacts extraordinarily. The capacity of three methods to demonstrate the affectability of the necessary leadership procedure is researched. Alpha cut and lambda esteem give and encourage considerable affectability investigation. All techniques are actualized to examine the reasonableness of the crop in the Indian nation. Test results when performed on Various Datasets, demonstrate that the proposed procedure removes more highlights just as gives more exactness when contrasted with existing techniques.
\end{abstract}

Key words: Analytic Hierarchy Process, Fuzzy Logic, Land Selection Investigation, Soft Computing

AMS subject classifications. 94D05

1. Introduction. Geographic Information System (GIS) of Land Selection Investigation (LSI)- based procedure connected to decide the appropriateness of a particular region for utilizing, i.e., it uncovers the suitability of territory for its reasonable or unsatisfactory. Likewise, this examination engaged with considering wide furies of criteria including ecological, social, and financial elements. Suitable treatment of such expansive and heterogeneous guide requires applying a flexible device. We will take a look at the reasonableness of parameters, similitude of settings with the notable climate and soil information gathered utilizing HFL. The community-oriented arrangement of suggestion falls under the recommender proposed yield. Conversely, the cost forecast and climate expectations. The blend of the Analytic Hierarchy Process (AHP) [1] and fuzzy sets settles on the decisions and choices progressively adaptable. HFL mirrors human personality when settling on choices dependent on surmised information and vulnerability. These techniques have scarcely been utilized in developing nations like India. This examination plans to show how incredible the FAHP (Fuzzy Analytic Hierarchy Process) strategy is in taking care of the LSI. For this propose, India, Tamil Nadu. Rangelands secure a broad zone of the district, and creature farming is the principal occupation of residents. The present investigation considered predominantly two parts of the environmental change effect over farming land, which

${ }^{*}$ The authors are grateful to the Indian Council of Social Science Research (ICSSR), New Delhi, for the financial support (No. IMPRESS/P580/278/2018-19/ICSSR) under IMPRESS Scheme. Authors express their gratitude to SASTRA Deemed University, Thanjavur, for providing the infrastructural facilities to carry out this research work.

${ }^{\dagger}$ Department of CSE, Sree Sakthi Engineering College, Coimbatore-641 104, India (sudhasengan@gmail.com)

${ }^{\ddagger}$ School of Computer Science and Engineering, University of New South Wales, Sydney, Australia (vijayakumar.varadarajan@gmail.com)

$\S$ Department of Computer Science, Wenzhou Kean University, Wenzhou Zhejing, China (sujatha.ssps@gmail.com)

IDept. of Computer Application, King College of Arts \& Science, Tiruchengode-637 215, India (drsguna9596@gmail.com)

" Department of Computational Intelligence, Vellore Institute of Technology, Vellore, India (csathiyakumar@yahoo.com)

**School of Computing, SASTRA Deemed University, Thanjavur, India (sharan.doit@gmail.com)

${ }^{\dagger \dagger}$ School of Computing, SASTRA Deemed University, Thanjavur, India (vsubramaniyaswamy@gmail.com), Corresponding Author 
incorporates [2], (i) Harvest profitability impact, and (ii) Soil natural carbon impact.

This study aims to present how powerful integrate the hybrid fuzzy set theory provides more sophisticated results as fuzzy set theories use advanced algorithms to address uncertainties, incompleteness, and vagueness and increase robustness associated with suitability criteria. The analytic hierarchy process is a multi-criteria method for assessing land-use suitability based on the Geographic Information System (GIS). The objective of this study was to identify suitable lands for crop production using Hybrid Fuzzy Logic techniques is in handling the land suitability analysis of Tamil Nadu. The paper highlights the use of different methods of land suitability evaluation for sustainable agriculture in developing India.

\section{Literature Review.}

2.1. An Overview of Land Evaluation. Just as various ways to deal with the procedure of land assessment, this section depicts an assortment of definitions and clarifications concerning arriving estimates. The [3] characterizes land assessment as the way toward evaluating the potential for elective sorts of land use and to anticipate the results of progress. It can recognize quantities of powers behind land assessment rising as a particular subject. Right off the bat, there is expanding the accessibility of biophysical information, and this information can be handled and exhibited in an assortment of ways. Also, nations are focusing on the difficulties of land-use scheduling. Dry Land areas (Ex: South Africa and Libya), have connected their feasible advancement objectives and land use scheduling. Thus, land-use scheduling can direct choices onto land use with the goal that they are put to the most practical method for the present while preserving a similar land for the future populace and their needs.

To decide its reasonableness/capacity, land assessment procedure might be done subjectively or quantitatively. Previously, a land assessment was utilized as a component of soil overview learning. Notwithstanding, since 1972 [4], land advancement has moved concentration to harvest development and creation, which incorporates viewpoints relating to atmosphere conditions, soil, and land administration. The following methodologies are used for LSI:

1. Farming creation by using mathematical terms influenced by parametric frameworks fuse land attributes. Numerous parametric methods have been used for land assessment. These methodologies shift in the particular parameters they incorporate and in their precise control.

2. Creation units as per the units shifting possibilities and restrictions influencing crop development concentrated on the arrangement of the property by Categorical frameworks [5].

The creative ability to utilize land deliberates investigation of both land's physical conditions and their effect on the present and future property for surveying Land assessment. The land assessment offers a system for looking at the changing ways that the area can be utilized, just like the advantages that might be gotten from these utilizations, considering the present and future financial and social conditions [6].

The land assessment procedure won't characterize the land use or any proposed changes in it. Instead, it gives information that can fill in as a reason for choosing which land choice utilization is appropriate. So, the land assessment helps land proprietors, provincial land advancement offices, and countries to touch base at intelligent land-use choices. In any case, there are absolute necessities for land assessment to be effectively used. A considerable lot of these prerequisites are explicit to the kind of land use, and they incorporate both the natural necessities of the harvest or other organic items and the requirements of the administration framework used to create it. The assessment of land assets is a mix of the properties of the land with the essentials of proposed land use [7].

The Framework for LSI is introduced by the standards of land assessment follows and represented in Fig. 2.1.

- Initial consultation, about the goal assessment concerned, information and presumptions characterizing

- The sorts of land use description to be considered, and foundation of their prerequisites that can bolster specific land use

- Base unit's asset description

- Land use of sorts' comparison

- Social examination and Economic

- Characterization of land appropriateness

- Presentation of the aftereffects of the assessment into a structure usable via land clients. 


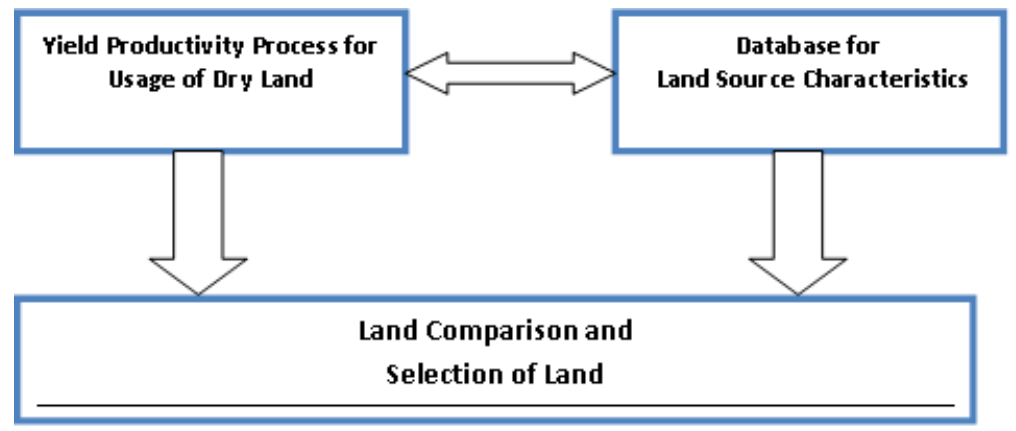

FIG. 2.1. Process of land selection evaluation.

2.2. The Need for Land Evaluation. The FAO contends that before, land use changes frequently occurred by slow development because of many separate choices taken by people. The expanded interest for physical space and sustenance from extending populace, the accessibility of reasonable land for generation making the land a rare asset, and even the less appropriate or minimal terrains had been exposed to development. A thorough evaluation of land is required. In developing nations, the developing requirement for increasingly profitable land types, the booking and safeguarding of land for horticulture, in addition to the growing worry to ensure the earth has made an interest for a complete survey of land space and its sanity. To accomplish this, what is required is a comprehensive stock of natural assets for a legitimate appraisal of land's appropriateness for creation purposes.

2.3. LSI and usage formation. Deciding reasonable land for a specific purpose is an intricate procedure, including numerous choices that may identify with biophysical, financial, and institutional/authoritative perspectives. An organized and steady way to deal with LSI is along these lines fundamental. Abiotic, biotic, and economic elements choose the accomplishment of a yield. Decisions concerning harvest worth ought to incorporate the abiotic, biotic, and business components that decide the productivity [8].

Land assessment of the FAO Framework is created from before land ability draws near. Here, by and large, land reasonableness of a land zone for specific land purposes is assessed from a lot of comparatively much autonomous land characteristics, which may each restrain the land-utilize probable. These assessments frequently arrange map units of healthy asset inventories. Like this, legend classifications of a soil study are characterized into appropriateness sub-classes, in light of the number and seriousness of confinements to land use. The FAO Framework detects the types of growing details indicated in Table 2.1.

TABLE 2.1

Formation of Land Selection Taxonomy.

\begin{tabular}{|l|l|}
\hline Taxonomy of Land Type & Description \\
\hline LSI: Class I & Type of selection \\
LSI: Class II & Selection of Land with degrees \\
LSI: Class III & Grouping the measurable scale factors of Land \\
LSI: Class IV & Land Service Management \\
\hline
\end{tabular}

The size of the estimation view appropriateness has two sorts of groupings in LSI structure [9, 10].

- Subjective: It utilized to assess ecological, social, and monetary criteria. The classes are determined depending on the physical generation capability of the land, generally used in surveillance examines.

- Measurable The types are characterized in like manner numerical relations, where the correlation between the goals is conceivable. Here extensive measure of monetary criteria is utilized.

Land appropriateness is a part of the assessment maintainability of land purpose. Rationality, together with weakness, characterizes the supportability of land. The supportable area should have the greatest appropriateness and least helplessness, and it represented in Fig. 2.2. 


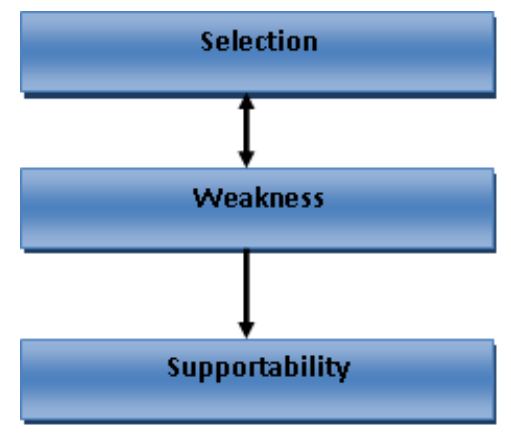

FIG. 2.2. Land Utilize Supportability.

2.4. Calculation Logic for Land Evaluation. Scientific models based on a land assessment on which there are numerous sorts of estimation logic. The primary ones are Boolean logic, HFL, and artificial neural systems.

2.4.1. Boolean Logic. A ruled-based methodology followed by the Boolean logic, where the cutoff points of sets are characterized, with the goal that a component does or does not have a place with a determinate set. It is the logic of true or false, generally utilized in the handy science, the rationale that pervades the FAO strategy. As indicated by that approach, the soil might be entirely reasonable, modestly appropriate, hardly intelligent, or not wise. There is no plausibility of depicting the slight differentiation between the classes, as in-between classes are not considered. As this strategy neglects to join the estimated idea of land information, there is developing mindfulness for an evaluation pattern that catches fuzziness, as found in the accompanying area [11].

2.4.2. Fuzzy Logic. FL characterized the term fuzziness, and he expressed, as multifaceted nature rises, exact articulations lose meaning and significant proclamations lose exactness [12]. From this announcement, Zadeh (1965) presented the idea of FL, where the reality of any report turns into a matter of degree. This hypothesis is an augmentation of regular Boolean logic that was acquainted with purpose the term of incomplete truth between totally evident and false. Zadeh has utilized this term as a way to demonstrate the uncertainty of natural language. However, the methodology has been connected to displaying numerous procedures that are mind-boggling and not well characterized.

An FL is a numerical method to describe and manage uncertainty in regular daily existence. FL demonstrated that one of the reasons that people have greater control than machines is that they are equipped for settling on effective choices due to inaccurate linguistic information. It specifies old-style sets hypothesis in which the enrollment level of any article to a collection constrained to the whole numbers 0 and 1 just by enabling the participants to take any certain amount somewhere in the range of 0 and 1 . By this definition, a fuzzy set is defined with uncertain limits in which the progress starting with one set then onto the next is continuous as opposed to sudden. Prior, the multi-criteria land reasonableness was surveyed more non-spatially, expecting the spatial uniformity over the region under thought. This, in any case, is ridiculous in cases like land reasonableness studies, where choices made utilizing criteria that change transversely over in space. Non-spatial predictable Multi-criteria Decision Making (MCDM) procedures routine or absolute the effects that are decided suitable for the entire zone under thought. To address the essential spatial leadership, MCD and Geographic Information Systems (GIS) can be coordinated.

Analytic Hierarchy Process (AHP) utilizes the framework by [13], Ideal Vector Approach, and Fuzzy AHP(FAHP). A multi-criteria basic leadership strategy is created using FL, and land reasonableness is investigated for horticultural harvests. Considerably more factors like soil, atmosphere, water system, framework, and financial elements considered. Be that as it may, restricted to a tiny region $(620 \mathrm{sq} . \mathrm{km})$ and confined to a solitary harvest (rice). 


\section{Material and Methods.}

3.1. Study area. Ramanathapuram District (RD) lies on the Southern Zone (SZ) and is limited on the east by Palk strait of RD-SZ, in the northwest by Virudhunagar and in North East (NE) by Sivagangai districts of the SZ, in the south by Gulf of Mannar of the SZ and in the NE by Pudukkottai district of the SZ. It is located at $9.05^{\circ}$ to $9.50^{\circ} / 78.10^{\circ}$ to $79.27^{\circ}$. The study is mentioned in Fig. 3.1.

On the SZ, RD lies and is limited in the east by Palk Strait of RD of the SZ, in the northwest by Virudhunagar and in NE by Sivagangai regions of the SZ, in the south by Gulf of Mannar of the SZ and in the North by Pudukkottai locale of the SZ. It located: $9.05^{\circ}$ to $9.50^{\circ} / 78.10^{\circ}$ to $79.27^{\circ}$. The study is referenced in Fig. 3.1.

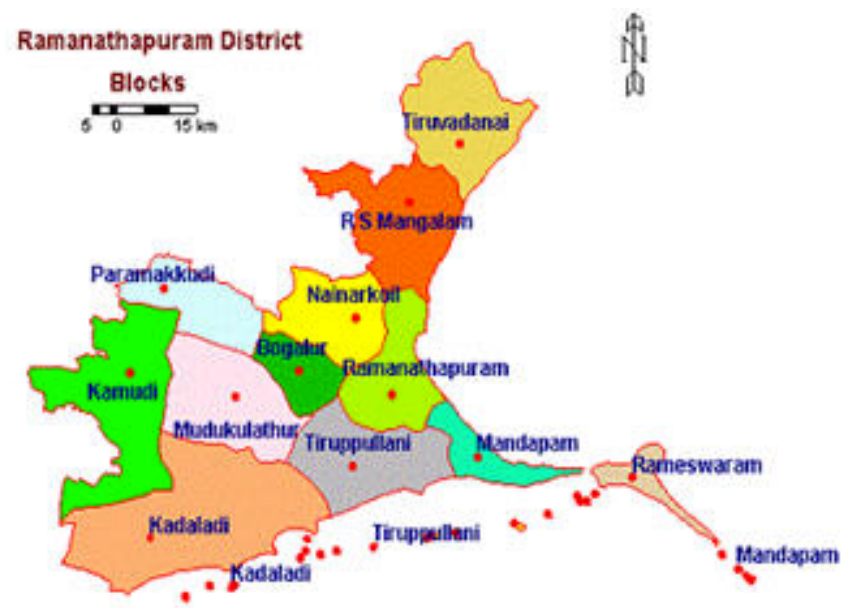

FIG. 3.1. LSI examination of RD.

The maximum temperature standard varies $29.2^{\circ}-37.8^{\circ} \mathrm{C} / 19.5^{\circ}-24.8^{\circ} \mathrm{C}$. During the long stretches of March, the contrast between the mean greatest and the mean least temperature is most elevated. By and large, the hum'idity rate extends $75 \%$ to $79 \%$. The most noteworthy relative percentage level of $85 \%$ is recorded during November, and the least relative moistness level of $75 \%$ is documented during May in this RD. The Wind speed is minimal during the period of October-November /October-March. The wind blows by and large from NE directions. South West (SW) breezes are transcendent from May to September. The primary wellspring of Irrigation water occurs in NE Monsoon. Typical yearly precipitation: 827.0 mm, Average Winter Rain: $67.4 \mathrm{~mm}$; Summertime: $122.7 \mathrm{~mm}$; SW Rainy season: $135.3 \mathrm{~mm}$ and NE Monsoon Drizzle: $501.6 \mathrm{~mm}$.

The RD soils can be varied into the primary types viz., clay, coastal alluvium, etc., Coastal alluvium happens in neighbor areas of RD. There are vast stretches of saline and underlying soils found in the waterfront squares. Rameswaram Island (RI) contains mostly sandy soil. The nitrogen status of the soil is demonstrated by the productiveness status of soil block is low, and phosphorus status of the soil is likewise moderate in all blocks aside from the nearest regions of $\mathrm{RD}$ where it is medium. The potash substance of soil is high in every one of the blocks. The mineral assets of the soil incorporate gypsum, limestone, and magnesium. While Mudukulatur and Kilakarai districts represent sizable stores of gypsum. RI contains enormous amounts of limestone stores. The area of the total cropped zone is $172469 \mathrm{~Hz}$. The territory under inundated farming is 63800. Hectare, while 137099 hectares, is under rainfed Agriculture. The significant nourishment grain yields developed are Paddy, Cholam, Cumbu, Ragi, and Blackgram. The significant non-sustenance yield produced in cotton.

3.2. The process of planning and decision-making. GIS was limited distinctly for the way toward mapping [14] in the early days for the utilization of remote detecting. In time progress in the data innovation created devices to utilize these maps during the time spent arranging and essential leadership. Land, being a 
valuable asset, requires to be overseen economically to help life on earth. Maintainable administration implies the usage of the accessible land assets so that the occupation, which is directed over a real portion of the property, is without or with least control over the assets.

The land utilization is feasible; the area should be utilized for a particular reason, which suits the confined conditions best. A horticultural territory should be described and assessed over its probability, restrictions, and imperatives that are affected by various Land Use Types (LUTs) [15]. The precise presentation of horticulture requests for the assessment of the land for the particular land use types in it. This LSI includes the interdisciplinary criteria running from financial to ecological. These numerous criteria that are affecting the LUT change over space, for example, standards, esteem change here and there, and are interrelated. Henceforth, there is an incredible requirement for the assessment of these criteria in spatial space. A few choices should be taken, and master information must be consolidated at different stages in the reasonableness examination, it indicates the following flow chart Fig. 3.2.

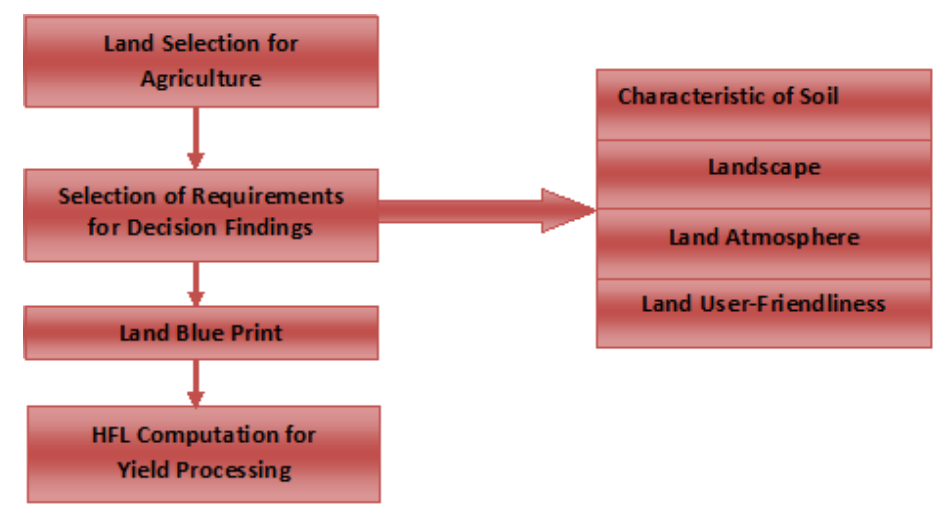

FIG. 3.2. Proposed Methodology for LSI.

\subsubsection{The procedure of MCDM ordered on a few criteria.}

1. Multi-Attribute / Multi-Objective Decision Making in light of how the criteria are being dealt with, as a trait/target.

2. Singular/Group Decision Making because of the number of individuals associated with the necessary leadership process.

3. Essential leadership under Certainty and Decision Making under Uncertainty, in light of the circumstance under which necessary guidance is being done and the idea of the criteria.

4. Proposed Framework of LSI-decision making. The decision-making problem of LSI for crops is analyzed using the Simons ideal with required adaptations. Fig. 4.1 depicts the abstract flow of the investigation method. LSI for farming crops investigated utilizing the Simons model with the fundamental leadership issue with necessary changes.

4.1. HFL approach in LSI. The HFL is an AHP position that evaluates various criteria using fuzzy numbers. While AHP depends on utilizing the Crisp numbers, FAHP has overcome the blemishes of AHP. Since uncertainty is a typical normal for some underlying leadership issues, the FAHP technique [16] has been created to make up for that defect. Hence HFL can dispense with the uncertainty and uncertainty from the appraisal with regards to confounded and multi-list issues, and it pointed in Fig. 4.2.

A triangular fluffy number communicates the overall quality of pair components in similar order and can be indicated as $M=(l, m, u)$ where $l \leq m c \leq u$. The limits $l, m, u$ show the min. Feasible value, the most encouraging value, and the most significant conceivable significance, separately, in a fuzzy occasion. A threesided sort enrollment capacity of $M$ fuzzy number can be portrayed as in Eqn. (4.1). Fig. 4.3, at the point when $l=m=u$, it is a non-fuzzy integer by principle. 


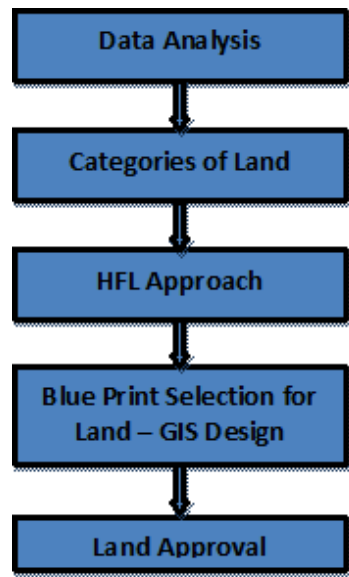

FIG. 4.1. Flow Chart of Land Selection Investigation.

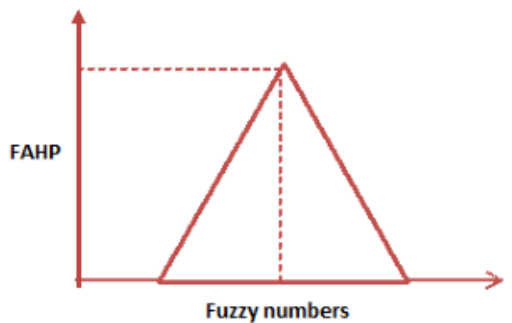

FiG. 4.2. Fuzzy triangular number.

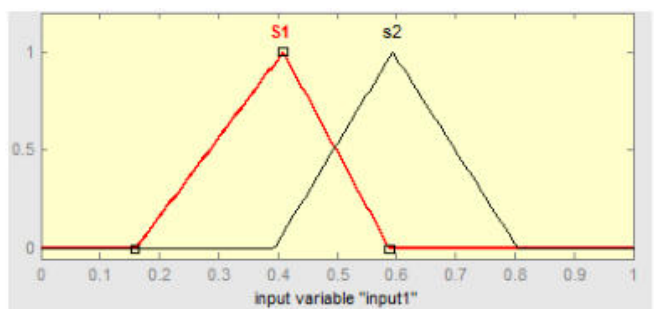

FIG. 4.3. The point of probability $V\left(S_{i} \geq S_{j}\right)$

$$
f(x)= \begin{cases}\frac{x-l}{m-l}, & l \leq x \leq m \\ \frac{u-x}{u-m}, & m \leq x \leq u \\ 0, & \text { otherwise }\end{cases}
$$

Various strategies have been displayed in literature, and the fuzzy examination [17] [18] is one of the techniques recommended. In the current analysis, the fuzzy investigation is connected because it is a more straightforward computation technique in correlation with other HFL strategies. Triangular fuzzy numbers utilized in A pairwise correlation network $\tilde{A}\left(a_{i j}\right)$, which could be scientifically communicated as pursues the following Eqn (4.2).

$$
\tilde{A}=\left(\tilde{a}_{i j}\right)=\left[\begin{array}{cccc}
(1,1,1) & \left(l_{12}, m_{12}, u_{12}\right) & \ldots & \left(l_{1 n}, m_{1 n}, u_{1 n}\right) \\
\left(l_{12}, m_{12}, u_{12}\right) & (1,1,1) & \ldots & \left(l_{2 n}, m_{2 n}, u_{2 n}\right) \\
\left(l_{12}, m_{12}, u_{12}\right) & \left(l_{2 n}, m_{2 n}, u_{2 n}\right) & \ldots & (1,1,1)
\end{array}\right]
$$




$$
\begin{aligned}
\tilde{a}_{i j}= & \left(l_{i j}, m_{i j}, u_{i j}\right) \\
\tilde{a}_{i j}^{-1}= & \left(1 / u_{i j}, 1 / m_{i j}, 1 / l_{i j}\right) \\
& i \text { and } j=1, \ldots, n, i \neq j
\end{aligned}
$$

\subsubsection{The steps of HFL exploration could be described as follows.}

1. Sum each row of the fuzzy comparison matrix $\tilde{A}$. Then standardize the row sums by the fuzzy arithmetic operation:

The means of fuzzy Chang's degree investigation could be clarified as pursues:

Initial step: Sum each line of the fuzzy examination framework $\tilde{A}$. At that point, standardize the column aggregates by the fuzzy number arithmetic activity, its denoted Eqns. (4.3) and (4.4).

$$
\begin{gathered}
\tilde{A}=\left(\tilde{a}_{i j}\right)_{n * n}=\left[\begin{array}{cccc}
(1,1,1) & \left(l_{12}, m_{12}, u_{12}\right) & \ldots & \left(l_{1 n}, m_{1 n}, u_{1 n}\right) \\
\left(l_{12}, m_{12}, u_{12}\right) & (1,1,1) & \ldots & \left(l_{2 n}, m_{2 n}, u_{2 n}\right) \\
\left(l_{12}, m_{12}, u_{12}\right) & \left(l_{2 n}, m_{2 n}, u_{2 n}\right) & \ldots & (1,1,1)
\end{array}\right] \\
\tilde{a}_{i j}=\left(l_{i j}, m_{i j}, u_{i j}\right) \\
\tilde{a}_{i j}^{-1}=\left(1 / u_{i j}, 1 / m_{i j}, 1 / l_{i j}\right) \\
\quad i \text { and } j=1, \ldots, n, i \neq j
\end{gathered}
$$

2. Compute the level of chance for $S_{i} \geq S_{j}$ by condition, refer the below Eqn. (4.5) and (4.6):

$$
\begin{gathered}
V\left(S_{i} \geq S_{j}\right)=\text { supply } \geq x\left[\min \left(S_{j}(x), S_{i}(y)\right)\right] \\
V=\left(\tilde{S}_{i} \geq \tilde{S}_{j}\right)= \begin{cases}\frac{u_{i}-l_{j}}{\left(u_{i}-m_{i}\right)+\left(m_{j}-l_{j}\right)}, & m \leq x \leq u \\
9, & \text { otherwise }\end{cases}
\end{gathered}
$$

3. Estimate the precedence vector $W=\left(w_{1}, \ldots, w_{n}\right) T$ of the fuzzy examination matrix $\tilde{A}$ as pursues, Eqn. (4.7):

$$
W_{i}=\frac{l_{i}+u_{i}+m_{i}}{3}, \quad i=1,2, \ldots, n
$$

4. Standardize the determined loads of every foundation as Eqn. (4.8):

$$
N W_{i}=\frac{W_{i}}{\sum_{j=1}^{n} w_{j}}, \quad i=1,2, \ldots, n, \text { where } \sum_{j=1}^{n} w_{j}=1, i=1,2, \ldots, n
$$

To play out a pairwise correlation among fuzzy factors, semantic elements have been characterized for a few degrees of inclination in Table 4.1.

The following equation determines a Stability Ratio (SR).

$$
S R=\frac{S_{i}}{R_{i}}, \quad S R=\frac{\lambda_{m x}-m}{m-1}
$$

where

$S R$ - random table

$\lambda$ - stability direction of the regular cost

$m$ - number of measures

$Z R$ - subjective table.

$S R$ is planned so that if $Z R<0.10$, the proportion shows a reasonable degree of consistency. Be that as it may, $Z R>0.10$ demonstrates conflicting decisions. The capacity of HFL in consolidating various kinds of information and the vulnerability technique for pair-wise examinations utilized to all the while by analyzing two bounds for the reasons for ordering land appropriateness for rice development in the investigation locales in India. 
TABLE 4.1

Triangular fuzzy number of semantic limits used in the test case.

\begin{tabular}{|c|c|c|c|c|c|c|}
\hline $\begin{array}{l}\text { Linguistic } \\
\text { Limits }\end{array}$ & \multicolumn{2}{|c|}{$\begin{array}{l}\text { Crisp Pairwise } \\
\text { Number }\end{array}$} & \multicolumn{2}{|c|}{ Fuzzy Values } & \multicolumn{2}{|c|}{$\begin{array}{l}\text { Common Triangular } \\
\text { Fuzzy Values }\end{array}$} \\
\hline Extreme & 9 & & $(9,9,9)$ & & $(0.11,0.11,0.11)$ & 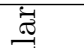 \\
\hline Very Strong & 7 & & $(6,7,8)$ & 塚 & $(0.12,0.14,0.16)$ & 50 \\
\hline Strong & 5 & है & $(4,5,6)$ & $50 \cdot 0$ & $(0.16,0.2,0.25)$ & 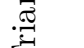 \\
\hline Moderate & 3 & సี పี & $(2,3,4)$ & .్త్రే & $(0.25,0.33,0.5)$ & E \\
\hline Equal & & & $(1,1,1)$ & E㞋 & $(1,1,1)$ & ర్ల \\
\hline Intermediate & $2,4,6,8$ & & $\begin{array}{l}(7,8,9), \\
(5,6,7), \\
(3,4,5), \\
(1,2,3)\end{array}$ & & $\begin{array}{l}(0.11,0.12,0.14), \\
(0.14,0.16,0.2), \\
(0.2,0.25,0.33), \\
(0.33,0.5,1)\end{array}$ & 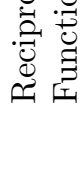 \\
\hline
\end{tabular}

\section{Result and Discussion.}

5.1. Implementation of the HFL in the context of LSI. HFL Contribution is the fundamental FL utilized in the HFL. The FL given by the specialists is fuzzified using triangular fuzzy numbers [19] (Table 5.1) to crop HFL (Table 5.2).

TABLE 5.1

LSI assessment environment

\begin{tabular}{|l|l|l|l|l|l|l|l|}
\hline \multirow{2}{*}{$e c$} & \multicolumn{7}{|c|}{$e$} \\
\cline { 2 - 7 } & NB & NM & NS & ZO & PS & PM & PB \\
\hline NB & PB & PB & PM & PS & PS & ZO & NS \\
NM & PM & PM & PM & PS & ZO & NS & NS \\
ZO & PM & PM & PS & ZO & NS & NM & NM \\
PM & PS & PS & ZO & NS & NS & NM & NM \\
PB & PS & ZO & NS & NM & NM & NM & NB \\
\hline PB - Positive Big, PM - Positive Medium, \\
PS - Positive Small, ZO - ZERO, \\
NB - Negative Big, NM - Negative Medium, \\
NS - Negative Small
\end{tabular}

TABLE 5.2

Fuzzified pair-wise assessment environment

\begin{tabular}{|l|l|l|l|l|l|}
\hline $\mathrm{CE}$ & $S_{1}$ & $S_{2}$ & $S_{3}$ & $N_{1}$ & $N_{2}$ \\
\hline$S_{1}$ & $(1,1,1)$ & $(1,3,5)$ & $(4,6,8)$ & $(6,8,10)$ & $(7,9,11)$ \\
$S_{2}$ & $(0.2,0.3,1)$ & $(1,1,1)(1,3,5)$ & $(1,3,5)$ & $(2,4,6)$ & $(3,5,7)$ \\
$S_{3}$ & $(0.1,0.1,0.2)$ & $(0.2,0.3,1)$ & $(1,1,1)$ & $(1,2,4)$ & $(1,3,5)$ \\
$N_{1}$ & $(0.1,0.1,0.1)$ & $(0.1,0.2,0.5)$ & $(0.2,0.5,1)$ & $(1,1,1)$ & $(1,2,4)$ \\
$N_{2}$ & $(0.09,0.11,0.14)$ & $(0.14,0.2,0.3)$ & $(0.2,0.3,1)$ & $(0.2,0.5,1)$ & $(1,1,1)$ \\
\hline
\end{tabular}

HFL presentation of the matrix is deliberate, as given by the HFL presentation below Fig. 5.1.

Taking into account that the $p h$ can be estimated with reasonable assurance, an alpha estimation of 0.612 is picked. It will produce the exhibition framework that limits esteems in Fig. 5.2.

To get a new weight framework from the range esteem grid is 0.578 is connected. The reason behind this is that measure how sure the master is with deference the factor being assessed. Worth 0.578 shows the master 


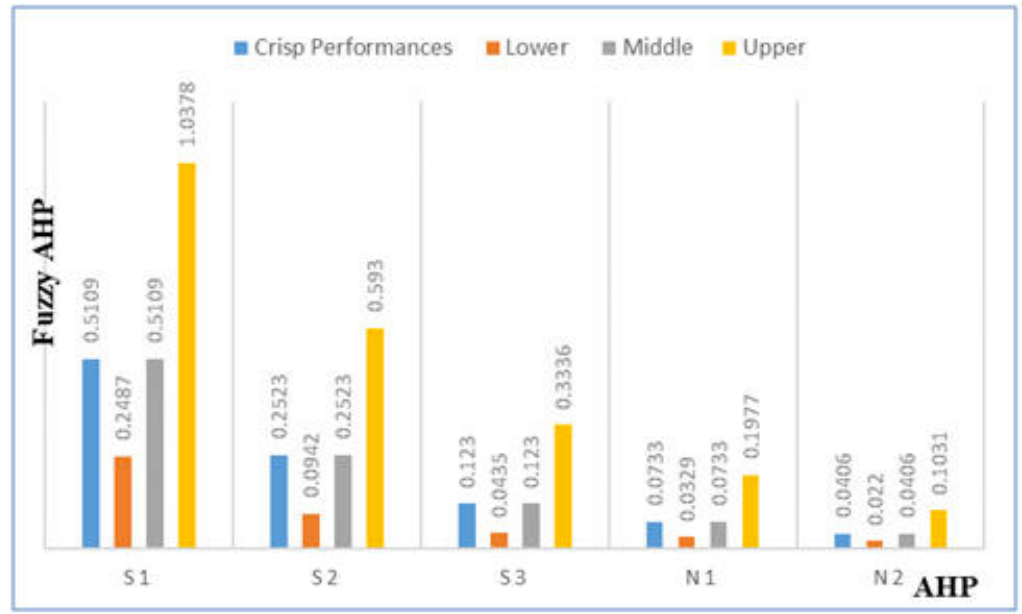

FIG. 5.1. Performances comparison of AHP and HFL.

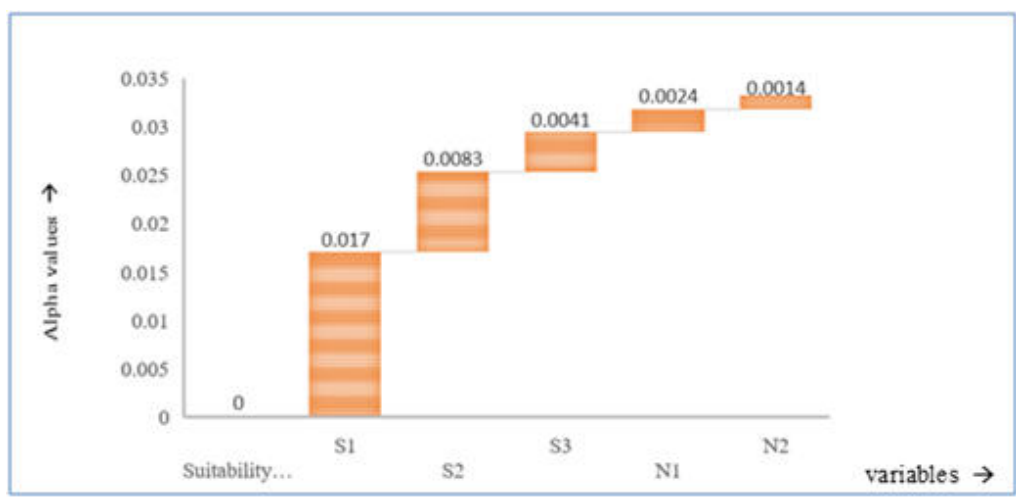

FIG. 5.2. Purpose of Alpha Cut review.

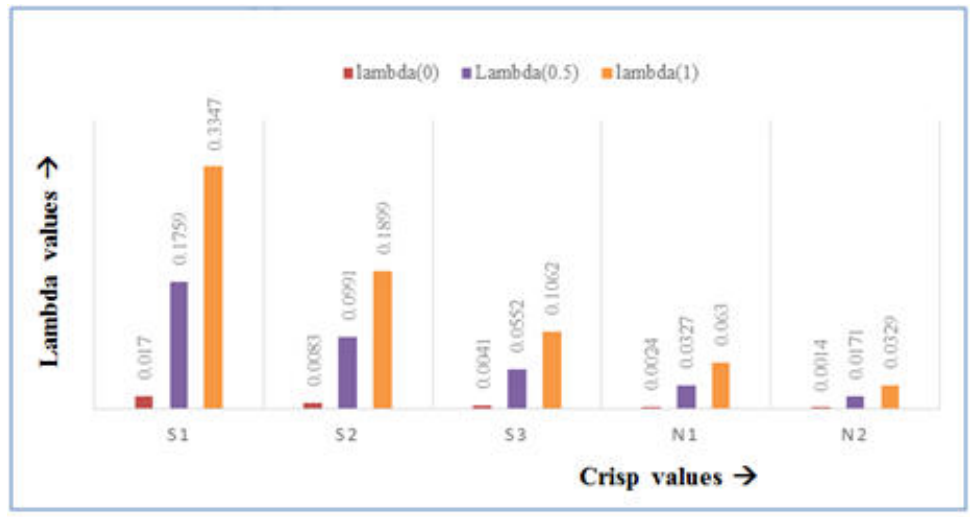

FIG. 5.3. Performance principles obtained at lambda values.

isn't that sure for his choices or inclinations, a certain measure of vulnerability exists in these inclinations and represented Fig. 5.3. 
5.2. Implementation of HFL. Contributions for the HFL approach are the fresh FL. The new FL is fuzzified utilizing the triangular enrollment works, as portrayed in passage 4.6. The FL for every reasonableness class is the contributions for fuzzy degree investigation to bring about fluffy exhibitions per appropriateness class. Similarly, the FL built by the examination among criteria in a gathering in the chain of command order is fuzzified to get fuzzy shows per standards. The fuzzy demonstrations for measures increased with fluffy presentations for classes. The augmentation executed over the chain of importance up to the primary level. In the last arrangement, these exhibitions handled with the alpha cut investigation and lambda capacities. The outcome of the methodology is portrayed in Fig. 5.4.

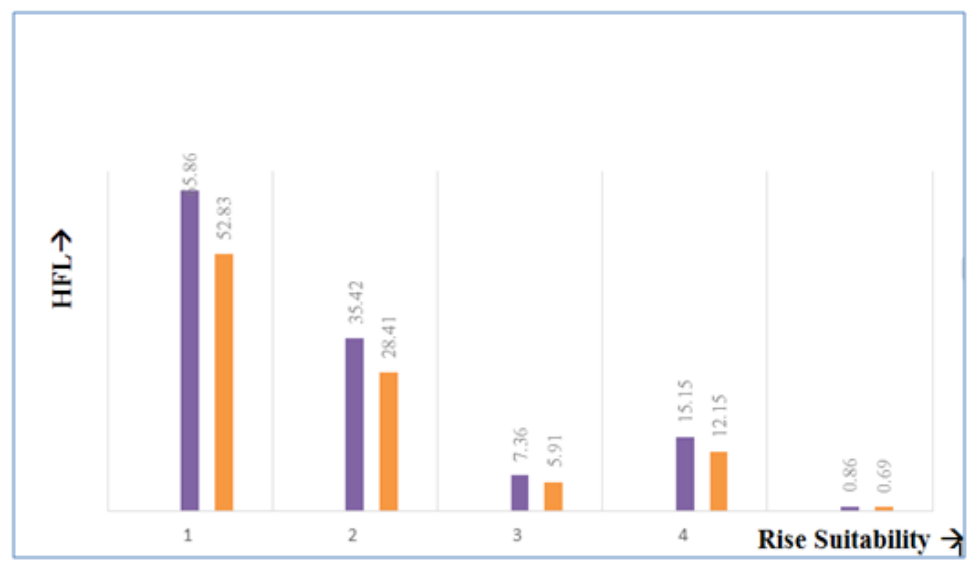

FIG. 5.4. Sample productiveness LSI area underclasses by HFL.

The appropriateness of the rice reasonableness is dissected utilizing HFL, with the alpha estimation of 0.6 showing the $60 \%$ vulnerability in the master learning about choosing the harvest appropriateness constraints and their prerequisites by the yield and the susceptibility over settling on their significance is connected is consolidated through the assurance list, lambda. At lambda $=0.578$, rice is exceptionally appropriate over $53 \%$ of the entire territory accessible for refinement $28.79 \%$ of the region is under reasonable appropriateness, 6.16 $\%$ under minimal reasonableness.

5.3. Proportional Estimation of LSI. The consequences of the three land reasonableness methodologies are assessed here for their capacities to display land appropriateness assessment and tending to vulnerabilities engaged with it the below Fig. 5.5.

It is apparent from the consequences of every one of the three approaches that most of the zone is appropriate for the harvested rice. In any event, over $70.12 \%$ of the region is reasonable for rice development. Less of the territory is under lower appropriateness classes. It is seen from the outcomes that the perfect vector method

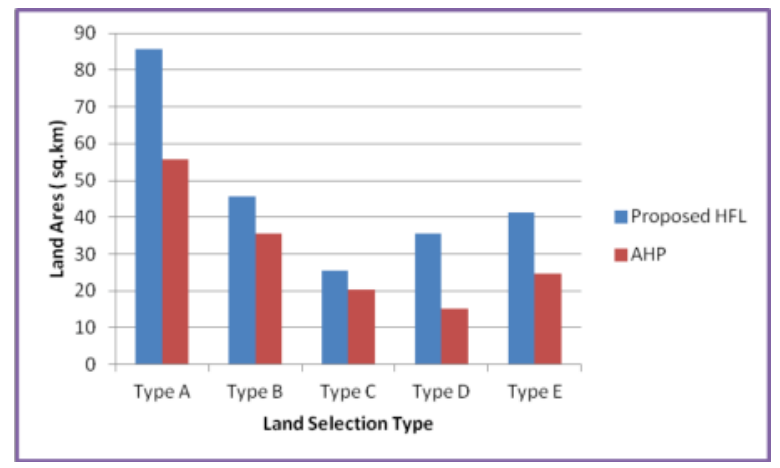

FIG. 5.5. Performance comparison of Land Utilization. 
has some biases towards $(-)$ and $(+)$ ideal qualities $\left(S_{1}, N_{2}\right) .(+)$ definite overstated, and the contrary goals smothered, which is unreasonable is the reason is that the likeness file, determined from $(+)$ and $(-)$ goals, prompts higher scores of $S_{1}$ and lower ratings of $N_{2}$. The consequences of the AHP approach are reasonable. These outcomes are practically identical to that of the HFL. Even though AHP fuses master information, it neglects to combine the vulnerability engaged with the master learning, his judgment, and conclusions. HFL gives impressively excellent outcomes. The methodology joins the weakness of master assessments while looking at the criteria.

Moreover, this methodology provides a chance to join a gap that may emerge while communicating the inclination over these criteria. For instance, one can't express his preference for the waste over a surface with high conviction. One can express his feeling like waste is progressively liked to surface. The alpha cut and negative values utilized in the estimation of the fluffy exhibitions join the vulnerability of different sorts. Alpha cut consolidates the vulnerability in deciding the yield prerequisite extents. For instance, when the alpha worth 0.658 considered for $\mathrm{pH}$, it thinks about the potential exhibitions between the range 0.0260: 0.457 for the class S1, which incorporates the qualities that may be scored by the class $S_{2}(0.0185: 0.2518)$. From this, it very well may be deduced that the alpha cut capacity tends to the vulnerability associated with the info information (e.g., $\mathrm{pH}$ guide) and it likewise contemplates the weakness that may emerge from the meaning of as far as possible $\left(S_{1}, S_{2}, S_{3}, N_{1}\right.$ and $\left.N_{2}\right)$. If the criteria estimated with more noteworthy vulnerability, at that point, quite possibly estimation of basis in a specific pixel may have a more extensive questionable range than one gauged with high vulnerability. Along these lines, the opinion of the alpha cut towards 0 demonstrates the higher vulnerability and thinks about the higher vulnerability with criteria. Those towards 1 speak to the assurance and have a tight scope of qualities. The esteem likewise measures weakness. Addresses the vulnerability that is associated with choosing the range of conditions gotten by the alpha cut. The worth will be towards 1 if the master or the leader is sure that the estimation of the foundation score is towards the most extreme evaluation of the unsure range. The worth will be towards 0 if the chief is increasingly sure that the estimate of the criteria score is towards the base estimation of the uncertain range.

5.3.1. Climate forecast of HFL. The climate forecast is assessed utilizing ten times cross approval, where $90.15 \%$ of information was being used for preparing, and $9.85 \%$ was being used for testing. Root means square of the distinction among genuine and anticipated qualities were found. Fig. 5.6 demonstrates the dispersion of average temperature blunder over every one of the areas. The legends speak to the scope of root mean square blunder rate while the pies speak to the level of locale falling under each range.

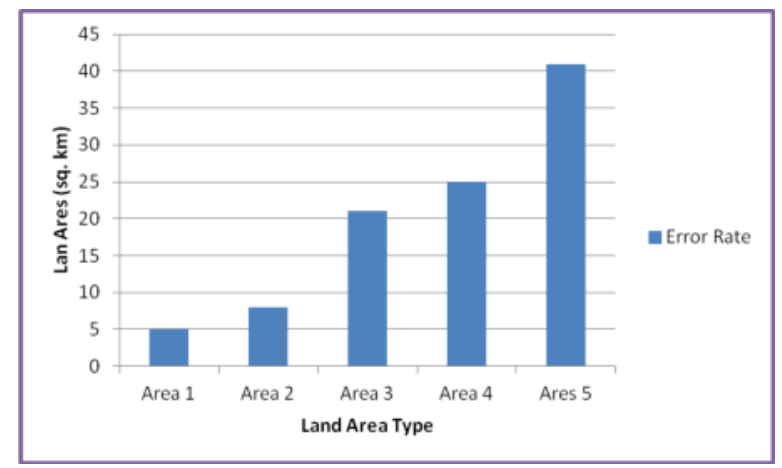

FIG. 5.6. Demonstrates the diffusion of standard temperature error rate.

The temperature consistently increments over time, and thus the root means square blunder worth is low than that of precipitation in the event of average temperature. If there should be an occurrence of rainfall, since precipitation sum won't wholly rely upon earlier year information, the blunder rate is high. Taking overcast spread, climatic weight can diminish the blunder rate for precipitation expectation.

5.3.2. Crop Forecast based on HFL. The harvests suggested have been contrasted, and the correct generation measurements dependent on zone and profitability in the locale. The Weightage given to the cost 
of the autumn in the last proposal is distinguished by setting it with an extent of $1 / 4$ and $1 / 3$. The relating results acquired are depicted in the chart that appeared in Fig. 5.7.

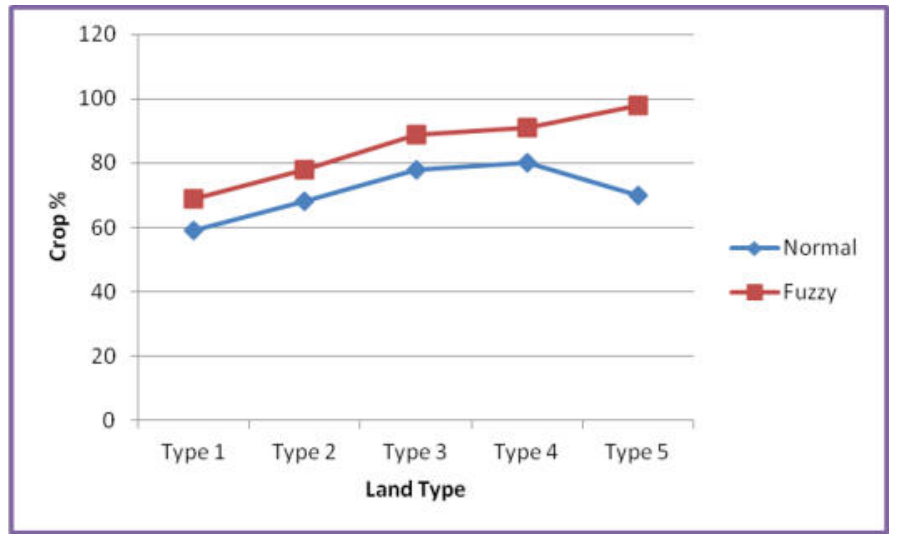

Fig. 5.7. Crop Forecast based on HFL.

A high Weightage for the expense isn't practical, as not every person can stand to deliver those yields. Consequently, authentic information additionally demonstrates less generation for those harvests. Henceforth the general review is low. The analysis tremendously influenced by the report of Rice harvest and Sugarcane. Indeed, even in a dry locale, for example, Ramanathapuram noteworthy information indicates the most astounding creation for rice, though the framework does not propose rice. It has caused a low review of $0.098,0.1346$ for the rice crop, for expense Weightage $1 / 4$ and $1 / 3$ separately. It demonstrates the ill-advised development in numerous locales. Correspondingly a few appropriate yields, for example, cashew nut, are not developed. Henceforth the approval with unique datasets influences a couple of explicit yields, which results in the general accuracy and review being controlled. The explanation behind a few yields not having a decent accuracy review is additionally because the help confirmations are a smaller value. It demonstrates that different yields may have smothered them during the fuzzy standard implication.

6. Conclusions and future work. Land reasonableness assessment is being completed without thinking about the vulnerability in the information, master learning. The land appropriateness assessment includes the criteria, which are in various scales extending from ostensible to proportion. Numerous contributions to the GIS-based land reasonableness assessment are the maps of the requirements, which are speaking to the perplexing, ceaseless, and unsure data in a primary ordered guide with the current limits among them. The Boolean procedures and other straightforward methods utilized for the land appropriateness assessment, which exasperates yields in the evaluation. To beat these issues, the present research investigates the probability of HFL. The objective of the examination is to expand the possibilities of the HFL into Land appropriateness necessary leadership. The aftereffects of execution assessment demonstrate an HFL of $65.554 \%$.

This exploration has a great deal of extension for further improvements. The proficiency of agribusiness HFL can be improved utilizing all the more preparing information and standards, which will enable it to be used in cultivating procedure recovery calculation additionally, which will profoundly lessen even the requirement for measurable cleaning. Fluffy principles can be stretched out to think about past soil utility, and soil surface utilizing remote detecting on agrarian land, which will build the exactness. Increasingly horticultural parameters can be distinguished to be incorporated into the framework either in HFL or as a different module. The crosssectional and top view pictures of soil can be handled to show signs of improvement thought regarding the dirt surface. The framework can likewise be incorporated with sensors that will give the daily report of soil and climate to help in system recommendation. As a sprouting space, there are as yet numerous prerequisites in horticulture that have not been investigated. 


\section{REFERENCES}

[1] Y. Y. JiAng, H. X. Zhang, K. Meng, AND J. JiE, Research and application of multi-criteria decision-making method based on order relation and rough set, Syst Eng Theory Pract., 27(6) (2007), pp. 161-165.

[2] S. DAS, AND S. KAR, Group decision making in the medical system: an intuitionistic fuzzy soft set approach, Appl. Soft Comput., 24 (2014), pp. 196-211.

[3] K. Gong, Z. XiaO, And X Zhang, The bijective soft set with its operations, Comput. Math Appl., 60(8) (2010), pp. $2270-2278$.

[4] D. Stanujkic, B. Djordjevic, And M. DJordjevic, Comparative analysis of some prominent MCDM methods: a case of ranking, Serbian banks. Serbian J Manag, 8(2) (2013), pp. 213-241.

[5] P. A. Burrough, Fuzzy mathematical methods for soil survey and land evaluation, Journal of Soil Science, 40 (1989), pp. $477-492$.

[6] T. R. Nisar Ahamed, K. Gopal Rao and J. S. R. Murthy, GIS-based fuzzy membership model for crop-land suitability analysis, Agricultural Systems, 63(2) (2000), pp. 75-95.

[7] FAO Soils Bulletin 32, A framework for land evaluation, 1981, Soil resources development and conservation service land and water development division, FAO and agriculture organization of the united nations, Rome 1976.

[8] H. Jiang, And J. R. Eastman, Application of Fuzzy Measures in Multi-criteria evaluation in GIS, International Journal of Geographic Information Science, 14(2) (2000), pp. 73-184.

[9] J. Malczewski, GIS-Based Land Use Suitability Analysis: A Critical Overview, Progress in Planning, 62(1) (2004), pp. 3-65.

[10] V. R. Thakare and H. M. Baradkar, Fuzzy System for Maximum Yield from Crops, Proceedings of National Level Technical Conference, (2013), pp. 4-9.

[11] S. C. Brown, P. J. Gregory, P. J. M. Cooper, And J. D. H. Keatinge, Root and shoot growth and water use of chickpea (Cicer arietinum) grown in dryland conditions: effects of sowing date and genotype, Journal of Agricultural Science, Cambridge, 113 (1989), pp. 41-49.

[12] F. TORRIERI, AND BAtÀ, A Spatial multi-criteria decision support system and strategic environmental assessment: A case study, Buildings, 7(4) (2017), pp. 96.

[13] H. Kazemi, And H. AKINCI, A land-use suitability model for rainfed farming by multi-criteria decision making analysis $(M C D A)$ and geographic information system (GIS), Ecological Engineering, 116 (2018), pp. 1-6.

[14] M. B. Mesgaran, K. Madani, H. Hashemi, and P. Azadi, Iran's land suitability for agriculture, Scientific Reports, 7(1) (2017), pp. 7670.

[15] Ingole, Kartik, Et Al., Crop Prediction and Detection using Fuzzy Logic in Matlab, International Journal of Advances in Engineering \& Technology, 6.5 (2013), pp. 2006.

[16] Jawad, Fahim, et Al., Analysis of Optimum Crop Cultivation using Fuzzy System, Computer and Information Science (ICIS), 2016 IEEE/ACIS 15th International Conference on. IEEE, 2016.

[17] J. Bosch, From software product lines to software ecosystems, Proceedings of the $13^{\text {th }}$ International software product line conference. Carnegie Mellon University, (2009), pp. 111-119.

[18] Bingen, Jim, Serrano, Alex, And Howard, Julie, Linking farmers to markets: different approaches to human capital development, Food Policy, 28(4) (2003), pp. 405-19.

[19] T. N. PraKash, Land suitability analysis for agricultural crops: a fuzzy multi-criteria decision-making approach, ITC, (2003, December).

Edited by: Rajkumar Rajasekaran

Received: Sep 19, 2019

Accepted: Apr 28, 2020 